\title{
A pós-graduação para os professores da educação básica: um estudo a partir dos planos estaduais de educação
}

\section{Post-graduation for basic education teachers: a study from state education plans}

\author{
Cleomar Locatelli*
}

\begin{abstract}
RESUMO
O artigo trata da pós-graduação como política de formação docente para educação básica. O objetivo é avaliar a extensão e a orientação que tal política alcança nos planos subnacionais de educação. A coleta de dados se deu, predominantemente, junto aos planos de educação dos 26 estados e do Distrito Federal. Constata-se que a pós-graduação para professores de educação básica, ainda que possa ser compreendida como um avanço para a realidade brasileira, comporta uma grande diversidade de tratamento em cada unidade da federação e sua efetivação, mesmo sendo uma meta institucional, dependerá, em grande medida, dos esforços individuais dos professores(as).

Palavras-chave: Pós-graduação. Formação docente. Educação Básica.
\end{abstract}

\begin{abstract}
The article deals with graduate studies as a teacher training policy for primary education. The objective is to evaluate the extent and orientation that such policies reach in the subnational educational plans. Data collection was predominantly carried out next to the education plans of 26 States and the Federal District. It can be observed that graduate studies for primary education teachers, although it can be understood as an advance for the Brazilian reality, holds a great diversity of treatment in each federation unit, and its effectiveness, as an institutional goal, will depend, in great measure, of the teacher's efforts.
\end{abstract}

Keywords: Postgraduate. Teacher training. Basic education.

${ }^{*}$ Universidade Federal do Tocantins. Campus de Tocantinópolis. Tocantinópolis, Tocantins, Brasil. E-mail: locatelli@uft.edu.br - http://orcid.org/0000-0003-0789-2104 


\section{Introdução}

Passados mais de quatro anos da aprovação do Plano Nacional de Educação (PNE 2014-2024), torna-se evidente que este compromisso público e estatal com a educação precisa ser acompanhado e avaliado em suas diversas dimensões. A quantificação e o aprazamento das metas com abrangência nacional foram também objeto de confirmação e/ou adequação por ocasião da elaboração dos Planos Estaduais e Municipais de Educação. E isso permitiu que o planejamento educacional nas esferas subnacionais, em diversos aspectos, pudesse ganhar definições específicas, moldando-se em função tanto de um diagnóstico local quanto das racionalidades ali presentes.

Embora com força de lei, como determina o Art. 214 da Constituição Federal (BRASIL, 1988), o PNE (2014-2024), tendo o objetivo de articular o sistema nacional de educação em regime de colaboração, não se estabelece por qualquer processo de imposição para com o planejamento nos estados e municípios. Ao contrário, pressupõe que se considere a autonomia e a especificidade de cada ente federado. Da mesma maneira, ainda que o PNE tenha sido construído numa perspectiva de generalidade, observando aspectos gerais que dizem respeito a toda a nação, o fato de estarmos tratando de um sistema nacional de educação em construção e de haver grandes dificuldades de definição sobre o chamado regime de colaboração, nos leva a perceber uma possível reconstrução de metas e estratégias para educação em nível local que merece atenção. A profundidade dessa reconstrução e suas consequências para o conjunto das metas do Plano Nacional, especialmente no que se refere a pósgraduação para formação docente na educação básica, serão objetos de análise no presente estudo.

Compreende-se que a avaliação de metas e estratégias do planejamento educacional brasileiro, que passa por diferentes níveis de governo, pressupõe tratar da inserção e relevância do processo de planejamento na realidade brasileira atual. Além disso, tratando-se de definir prioridades para a política pública de educação, que implica na mobilização das estruturas estatais para interesses coletivos e enfrentamento de uma histórica dívida social, devemos compreender que não se faz sem afetar privilégios e grupos de interesse.

Como já alertou Calazans (1996, p. 11),

Num país com um sistema capitalista marcadamente excludente, como o Brasil, com tão elevada dívida social, certamente os "planos econômicos" ou de "desenvolvimento global" e, muito menos, os Planos Nacionais 
de Educação não podem exercer papel determinante (mesmo quando produzem e alteram algumas evoluções), se tomados isoladamente.

No entanto, como adverte a própria autora, esse fato não deve nos desestimular ao debate da questão, visto que as ações do Estado representam a condensação dos conflitos existentes na sociedade. Ou seja, trata-se de um espaço de confronto entre as diversas forças e interesses existentes. Por isso, se de um lado o planejamento, não devendo ser tomado como uma ação puramente técnica (neutra) e nem como um processo revolucionário que garantirá amplas e significativas mudança (CALAZANS, 1996), por outro, além das experiências e práticas sociais transformadoras que se desenvolvem no interior das escolas, o planejamento educacional pode favorecer a retomada do debate, a articulação permanente e a resistência em favor de ações que representem as necessidades da população e os resultados das lutas sociais.

Assim, o propósito do presente trabalho é avaliar a extensão e a orientação da política de pós-graduação para os professores da educação básica, considerando o processo de planejamento realizado pelos estados brasileiros, na confluência do Plano Nacional de Educação (PNE/2014). Trata-se, portanto, de um estudo documental precedido de uma discussão conceitual em torno da pós-graduação como alternativa para formação continuada dos professores da educação básica.

Especificamente, quanto ao recorte da análise, procuramos levantar informações sobre dois aspectos que consideramos relevantes par a compreensão do objeto: o primeiro refere-se às metas e estratégias dos Planos Estaduais de Educação (PEE's), que tratam da pós-graduação para formação docente na educação básica e o segundo, trata das possibilidades, em cada unidade da federação, para o afastamento remunerado e outras formas de apoio para a consecução de tal política.

\section{A pós-graduação como uma perspectiva para a formação dos professores na educação básica}

Antes de tratarmos propriamente da expansão da pós-graduação junto aos professores da educação básica e das perspectivas apresentadas nos Planos Estaduais de educação, consideramos necessário refletir, ainda que brevemente, sobre a natureza e objetivos desses cursos. 
Primeiramente, visto que estamos tratando de uma etapa de formação que se realiza no momento seguinte da graduação, podemos perceber que sua caraterística mais geral se impõe por ter como pré-requisito a conclusão de um curso superior. Em seguida, considerando sua segmentação, vamos notar que a pós-graduação se constitui a partir de dois grandes caminhos ou possibilidades: 1) a continuidade de um processo educativo que ainda tem como centralidade o ensino, constituindo-se num aperfeiçoamento das matérias ou temáticas da graduação, sendo, portanto, um aprofundamento ou prolongamento da formação inicial; ou 2) o desenvolvimento de um processo formativo que se estabelece na e pela pesquisa.

Saviani (2017) vê essa diferenciação na caraterização da pós-graduação lato e stricto sensu:

Os cursos de pós-graduação lato sensu assumem dominantemente as formas de aperfeiçoamento e especialização e constituem uma espécie de prolongamento da graduação. De fato, esses cursos visam a um aprimoramento (aperfeiçoamento) ou aprofundamento (especialização) da formação profissional básica obtida no curso de graduação correspondente. Em contrapartida, a pós-graduação stricto sensu, organizada sob as formas de mestrado e doutorado, possui um objetivo próprio, [...] se volta para a formação acadêmica traduzida especificamente no objetivo de formação de pesquisadores (SAVIANI, 2017, p. 4-5).

Nesse sentindo, como definido por Saviani (2017), assim como a graduação está relacionada a uma formação profissional, também a pós-graduação lato sensu, como uma continuidade do processo de formação em nível superior, terá como justificativa as próprias alterações ocorridas na respectiva área de conhecimento, no sentido de possibilitar o encontro com os avanços de pesquisas e mudanças no campo profissional.

Assim, tratando-se de formação continuada dos professores de educação básica, não devemos desconsiderar a importante relação que a pós-graduação lato sensu terá com a realidade das escolas, da prática educativa e dos cursos de licenciatura. Sendo, portanto, pertinente considerar, para uma análise crítica dos referidos cursos na área de educação, que as expectativas constituídas já na graduação, sobre uma possível aplicação direta do que se estuda, como se fosse uma questão de manipulação ou emprego direto baseada numa técnica ou jeito de fazer, poderão também estar presentes nos cursos de pós-graduação. "Essas noções descontextualizadas têm se constituído num forte aparato (ideológico inclusive) para formações cada vez mais focadas no saber fazer e distanciadas do domínio conceitual" (SILVA; JACOMINI, 2017, p. 644). 
É fato que os estudos educacionais continuam a se deparar com temas e situações complexas. Sendo um desafio a mais a necessidade de superar o pensamento espontâneo ou da linguagem utilitarista dos tempos atuais. E não seria honesto tentar defender ou querer acreditar que os grandes desafios da educação serão adequadamente enfrentados, ignorando-se o desenvolvimento teórico da educação e das ciências afins.

Para Ball (2011, p. 93), a teoria é um veículo para pensar diferente, ela "Oferece uma linguagem rigorosa e irônica para além do contingente". Nesse sentido, nos damos conta que o propósito da teoria, que parece algo bastante óbvio, precisa ser resgatado, precisa ser compreendido e ressignificado. $\mathrm{Ou}$ seja, faz-se necessário relembrar, como faz Ball (2011, p. 93), que a teoria tem como finalidade "desfamiliarizar práticas e categorias vigentes", permitindo revelar aspectos ocultos da realidade e abrir caminhos para novas invenções e novas experiências.

Portanto, embora sendo um prolongamento da formação profissional e uma formação continuada, a pós-graduação lato sensu, ao tratar da escola e dos processos de aprendizados, não deve reproduzir ali uma visão de senso comum ou uma compreensão superficial da realidade. Também não pode ser apenas uma demarcação de status pela atribuição de uma certificação, agregando pouco ou nada para um desenvolvimento profissional e para a sua postura crítica diante da realidade. Ao contrário, precisa contribuir ativamente para o papel de sujeito e de intelectual que o professor vai assumir no interior da escola e perante a sociedade.

Contudo, se a pós-graduação lato sensu se constitui como um processo de continuidade em relação a formação inicial (a graduação), possivelmente as fragilidades da graduação se estendem para a pós, principalmente quando se concebe este último como um mero treinamento ou processo de certificação. Ainda que não possamos tomar a pós-graduação como uma ação capaz de compensar as fragilidades teóricas da graduação, a ausência de requisitos mínimos de exigências (FONSECA, 2004), que possam contribuir para o desenvolvimento intelectual docente ou para uma análise rigorosa da realidade educativa, torna o investimento nesse tipo de formação pouco significativo para determinar a qualidade da preparação para o magistério.

Com base nas Sinopses Estatísticas da Educação Básica - 2017, (BRASIL, 2018 b), podemos perceber que é extremamente baixo o percentual dos professores da educação básica que possuem mestrado ou doutorado: 2,42\% tinham mestrado e $0,43 \%$ doutorado em 2017 . No entanto, se considerarmos a pós-graduação lato sensu encontramos uma situação diferente. Olhando especificamente aqueles que haviam concluído um curso de especialização em 2017, eram mais de 749 mil, ou 34,18\% do total. Sendo observado um aumento na ordem de mais de $3 \%$ num período de dois anos. Ou seja, verifica-se que 
entre 2015 e 2017, mais de 67 mil professores da educação básica concluíram a especialização. Ao mesmo tempo em que "[..] nos últimos quatro anos o número de matriculados em cursos de especialização lato sensu e MBA cresceu $74 \%$, saltando de 683 mil alunos para quase 1,2 milhão. Grande parte desses alunos frequenta instituições privadas [...]" (KUZUYABU, 2020, p. 1).

Assim, tendo em vista os níveis de abrangência dos cursos de pósgraduação lato sensu junto ao pessoal docente da educação básica e, sobretudo, os sérios problemas quanto aos seus objetivos e controle de qualidade, faz-se necessário atentar para a expansão desordenada e o predomínio absoluto de interesses mercadológicos nessa área. Segundo Fonseca (2004), na realidade brasileira, esses cursos sofreram uma perda de identidade com a separação entre o stricto e o lato sensu, caracterizando-se, na atualidade, por uma excessiva mercantilização e por uma ausência de regulação ou avaliação que possam impactar na sua qualidade.

Ainda sobre os cursos de pós-graduação lato sensu, faz-se necessário destacar que, com a desregulamentação promovida pela Resolução CNE/ CES $n^{\circ}$ 1, de 2001 (BRASIL, 2001), cuja oferta independe de autorização, reconhecimento, e renovação de reconhecimento, além das exigências de qualidade do corpo docente, a formação didático-pedagógica e a formação científica deixaram de ser obrigatórias. Como afirma Fonseca (2004, p. 179):

Se, a partir daí, houve um crescimento desordenado e uma oferta sem qualidade, isso foi auxiliado, num primeiro plano, pela própria política de ensino superior, aquiescida pelo Conselho Nacional de Educação (CNE), ao flexibilizar as normas de funcionamento desse nível de ensino.

Por outro lado, faz-se necessário destacar, considerando os estudos de Cunha (1974), que o desenvolvimento da pós-graduação tem sido feito no Brasil, tendo como objetivo principal, razões de ordem técnica e social. No caso das funções técnicas da pós-graduação, conforme observado pelo autor, o Ministério da Educação relacionava, em 1965, três grandes motivos para o desenvolvimento da pós-graduação: a) formação docente para atuar na graduação; b) preparação de pesquisadores; e c) treinar técnicos e trabalhadores intelectuais para o desenvolvimento nacional.

Quanto ao objetivo social, considerando que houve uma perda do valor simbólico e econômico do diploma de graduação, a pós-graduação teria assumido esse papel. 
Como o número de graduados aumentou a um ritmo acelerado, o valor do diploma de graduação caiu: sua posse deixou de ser distintiva, não indica mais que o graduado é "naturalmente" adequado para as ocupações que exigem maior "qualificação" e "responsabilidade", e, em conseqüência, são mais bem remuneradoras (CUNHA, 1974, p. 69).

Percebe-se, que no caso dos professores de educação básica, não estando presente os objetivos técnicos (preparar para lecionar na graduação, formação intelectual e para pesquisa), devido a condição das especializações destacadas acima, se sobressai o objetivo social da pós-graduação. Ou seja, se o diploma de graduação não serve mais como distintivo em relação ao conjunto da massa, visto que se tornou comum, a pós-graduação se constitui como uma nova meta de diferenciação, um novo sonho que encontra no lato sensu o caminho mais fácil.

\section{A pós-graduação e o afastamento remunerado para formação no Plano Nacional de Educação (2014)}

Em relação ao Plano Nacional de Educação (PNE, 2014-2024) analisamos aqui a meta 16 , por ser aquela que trata especificamente da pós-graduação para os professores da educação básica. Analisamos também a estratégia quatro da meta 18, que trata do afastamento remunerado para formação. Consideramos estes dois aspectos (pós-graduação e afastamento remunerado) constituintes de uma mesma realidade, principalmente se a pós-graduação, pressupondo apresentar resultados concretos no sentido de contribuir para o enfrentamento dos desafios atuais da escola, possa ser compreendida como parte da política de formação docente para educação básica.

Conforme descrito na meta 16, pretende-se "formar, em nível de pósgraduação, $50 \%$ (cinquenta por cento) dos professores da educação básica, até o último ano de vigência deste PNE [...]" (BRASIL, 2014). Na apresentação dessa meta duas questões nos chamam atenção: a primeira diz respeito ao direcionamento da pós-graduação para os professores de educação básica. A segunda, trata do alto índice a ser alcançado até o final da década.

Colocar a pós-graduação como meta para formação dos professores da educação básica, no planejamento educacional, revela-se uma novidade para a realidade brasileira. Como destacamos anteriormente, segundo Cunha (1974), a pós-graduação no Brasil, conforme os próprios documentos oficiais, sempre teve como objetivo a formação docente para lecionar nos cursos de graduação e para a formação de pesquisadores. No âmbito da educação básica, desde 
a promulgação da Lei de Diretrizes e Bases da Educação - LDB n 9394/96 (BRASIL, 1996), travou-se um importante debate sobre a obrigatoriedade ou não da formação de nível superior.

Sendo necessário ressaltar que, embora a LDB n 9.394/96, no Art. 87, § $4^{\circ}$ (BRASIL, 1996), das disposições transitórias, tenha estabelecido que "Até o fim da Década da Educação somente serão admitidos professores habilitados em nível superior ou formados por treinamento em serviço”, essa determinação não foi cumprida. E assim, a admissão de professores com formação de nível médio permanece em vigor, mesmo com a nova redação dada pela Lei $\mathrm{n}^{\circ} 12.796$, de 2013 ao Art. 62 (BRASIL, 2013). Ou seja, no Brasil, ainda se admite “[...] como formação mínima para o exercício do magistério na educação infantil e nos 5 (cinco) primeiros anos do ensino fundamental, a oferecida em nível médio na modalidade normal". Nesse sentido, consideramos haver aqui uma realidade um tanto quanto contraditória: se ainda admitimos professores sem formação de nível superior na educação básica, como estabelecer uma meta de alcançar tantos professores com pós-graduação?

Outro ponto que nos chama atenção, diz respeito ao índice de $50 \%$ dos professores a serem pós-graduados até o final da década. Essa meta pode ser avaliada totalmente irreal se considerarmos apenas a pós-graduação stricto sensu, visto que o número de mestres e doutores, em 2017, não chegava a $3 \%$ do quadro docente da educação básica. Sendo necessário, no entanto, considerar o lato sensu, as chamadas especializações, para que se tenha uma possível aproximação ou alcance da meta. Nesse último caso há que se admitir outro fato no mínimo contraditório. Senão vejamos: como se estabelece uma meta, em termos de preparação docente, para um nível de formação (a pós-graduação lato sensu) que não tem sido objeto de regulação, avaliação ou controle por parte do Estado? Como desconhecer as dificuldades relativas à qualidade e à validade dos certificados de pós-graduação lato sensu no Brasil?

Ainda a respeito da meta 16 - PNE (2014-2024), devemos considerar os seguintes aspectos: primeiro, a referida meta trata tanto da pós-graduação para os professores da educação básica, quanto da formação continuada para todos os profissionais da educação. Segundo, são apenas seis estratégias para a descrição da realização dessa meta, sendo que a grande maioria aborda mais diretamente a formação continuada, como é o caso da composição de acervo de obras didáticas, paradidáticas, literatura e de dicionários; a consolidação do portal eletrônico para subsidiar a atuação dos professores e das professoras da educação básica; e a implementação das ações do Plano Nacional do Livro e Leitura. E terceiro, podemos considerar que apenas a estratégia 16.5 aborda diretamente a pós-graduação, quando propõe "ampliar a oferta de bolsas de estudo para pósgraduação dos professores e das professoras e demais profissionais da educação 
básica" (BRASIL, 2014). Havendo, portanto, uma certa fragilidade em relação a estrutura dessa meta como uma política pública.

Nesse sentido, do ponto de vista das ações que possam ser realizadas por iniciativa de um programa nacional de formação docente, sobretudo com a participação direta do governo federal e que poderia resultar num fomento ao mestrado e ao doutorado, encontramos apenas a proposta de ampliação da oferta de bolsas. As demais iniciativas ficam sob a responsabilidade dos governos estaduais ou municipais e/ou para uma responsabilização direta dos próprios professores.

Sobre o processo de realização ou de alcance das metas do PNE (20142024), considerando as avaliações já realizadas e expostas no Relatório do Segundo Ciclo de Monitoramento (BRASIL, 2018a, p. 271), verifica-se que: "[...] no âmbito nacional, faltam 13,8 p.p. para que a meta [16] seja alcançada, ou seja, para que $50 \%$ dos professores da educação básica tenham formação em nível de pós-graduação até 2024". O relatório destaca que o crescimento anual da pós-graduação entre os professores da educação básica tem sido de 1,3 p.p., uma média insuficiente para alcança a meta.

Outro fato importante destacado pelo relatório é que o "crescimento do percentual de mestres e doutores entre os professores da educação básica revela um ritmo quase imperceptível quando comparado com o de especialistas [...]". Ficando claro que são os cursos de especialização que estão ao alcance dos professores. A pós-graduação stricto sensu, que apresenta uma significativa estruturação, regulamentação e controle institucional, tem ficado distante da realidade dos professores da educação básica. Sendo perceptível também que os professores com mestrado ou doutorado estão ligados à rede federal de ensino ou pertencentes às regiões sul e sudeste do país.

A meta 18 do PNE (2014-2024), que trata da "existência de planos de Carreira para os (as) profissionais da educação básica e superior pública de todos os sistemas de ensino, [...]" (BRASIL, 2014) se refere à licença remunerada na estratégia 18.4, quando estabelece a previsão "nos planos de Carreira dos profissionais da educação dos estados, do Distrito Federal e dos Municípios, [de] licenças remuneradas e incentivos para qualificação profissional, inclusive em nível de pós-graduação stricto sensu".

Embora essa seja a única referência do PNE (2014-2024) sobre a licença remunerada, ela não deixa dúvida quanto à necessidade de tal licença e da orientação para que ela venha constar nos planos de Carreira dos profissionais da educação. Além disso, podemos observar duas outras particularidades dessa orientação/determinação: primeiro que além da licença remunerada inclui incentivos para qualificação profissional, sendo compreendido como bolsas de estudos, entre outros. O segundo diz respeito ao destaque: "inclusive em nível 
de pós-graduação stricto sensu", de forma que não houvesse uma omissão ou uma exclusividade para o mestrado e doutorado.

Essas informações nos levam a verificar a abordagem da pós-graduação para formação docente na educação básica construída na perspectiva dos planos de educação dos estados e do Distrito Federal. Buscamos levantar os destaques que devem concorrer diretamente para o compromisso e engajamento dos planos subnacionais com a questão, ou seja, como cada uma das unidades da federação menciona, em seu planejamento, a questão da pós-graduação e do afastamento remunerado para formação.

\section{A pós-graduação e o afastamento remunerado para formação nos planos de educação dos estados e do Distrito Federal.}

No que se refere a abordagem da pós-graduação para formação docente na educação básica, buscamos considerar primeiramente a definição dos percentuais a serem alcançados, se acompanha ou não o que foi definido pelo Plano Nacional Educação. Em seguida, verificamos outros três aspectos relacionados: as referências em relação ao nível de formação stricto sensu; a possível gratuidade dos cursos ofertados para os professores e o segmento administrativo para realização da pós-graduação, se em instituição pública ou privada.

Em relação ao afastamento remunerado para formação, procurou-se avaliar os seguintes aspectos: primeiro, se há garantia de licença para estudo; segundo, se há garantia de licença remunerada para estudos; terceiro, se é para pós-graduação de maneira geral; quarto, se é somente para pós-graduação stricto sensu; quinto, se estabelece cotas no universo de professores; e sexto, se prevê bolsas de estudo além da licença remunerada.

Como podemos ver no Quadro 1, embora a maioria dos estados siga a meta nacional de alcançar $50 \%$ de professores com pós-graduação, verificamos que há aqueles que definem percentuais menores, como os estados de Pernambuco (2015) 37,4\% e Maranhão (2014) 40\% e outros que definem metas mais ousadas, como Roraima (2015), Piauí (2015) e Distrito Federal (2015) 100\%, Espírito Santo (2015) 90\%, Rio Grande do Sul (2015) 80\%, Santa Catarina (2015) 75\%, Paraná (2015) 70\% e Amazonas (2015) e Mato Grosso do Sul (2014) 60\%. Verificamos ainda que os estados do Tocantins (2015) e Mato Grosso (2014) não definiram nenhuma meta nesse sentido.

Sobre a apresentação de metas específicas para a pós-graduação stricto sensu, verificamos que, embora a maioria tenha feito referência a esse tipo de 
curso, foram poucos os Planos Estaduais de Educação que trataram a questão de maneira específica, definindo um percentual ou um número de professores que concluíram o mestrado ou doutorado até o final da década. A análise dos dados revela que três estados: Ceará, Mato Grosso e Tocantins, tratam de uma expansão ou ampliação do número de professores com pós-graduação stricto sensu, sendo que apenas o estado do Tocantins estabelece um patamar a ser alcançado, de $10 \%$ de crescimento em relação ao quadro de doutores atuais e de $30 \%$ no quadro de mestres atuais. Os estados que estabelecem um percentual com base no universo do quadro docente são: Rondônia (2015), que quer chegar a $10 \%$ de mestres e doutores e Piauí que quer chegar a $30 \%$. Também o Distrito Federal estabelece como meta chegar a 33\% de mestres e 3\% de doutores em sua rede de ensino.

QUADRO 1 - AS ABORDAGENS SOBRE A PÓS-GRADUAÇÃO NOS PLANOS ESTADUAIS DE EDUCAÇÃO

\begin{tabular}{|c|c|c|c|c|}
\hline Estados & $\begin{array}{l}\text { Percentual a ser } \\
\text { alcançado até o } \\
\text { final da década }\end{array}$ & $\begin{array}{l}\text { Apresenta metas } \\
\text { à pós-graduação } \\
\text { stricto sensu }\end{array}$ & $\begin{array}{l}\text { Trata da oferta } \\
\text { de pós-graduação } \\
\text { gratuita para os } \\
\text { professores? }\end{array}$ & $\begin{array}{l}\text { Trata da realização } \\
\text { exclusiva em } \\
\text { Instituições Públicas } \\
\text { de Ensino Superior }\end{array}$ \\
\hline $\mathrm{AC}$ & $50 \%$ & Não & Não & Não \\
\hline AP & $50 \%$ & Não & Não & Não \\
\hline $\mathrm{AM}$ & $60 \%$ & Não & Não & Não \\
\hline PA & $50 \%$ & Não & Não & Não \\
\hline $\mathrm{RO}$ & $100 \%$ & $10 \%$ & Sim & Prioritariamente \\
\hline $\mathrm{RR}$ & $50 \%$ & Não & Não & Não \\
\hline TO & -- & $\begin{array}{c}\text { Ampliar } 30 \% \mathrm{M} \\
10 \% \mathrm{D}\end{array}$ & Sim & Sim \\
\hline $\mathrm{AL}$ & $50 \%$ & Não & Não & Não \\
\hline BA & $50 \%$ & Não & Não & Não \\
\hline $\mathrm{CE}$ & $50 \%$ & Ampliação & Não & Não \\
\hline MA & $40 \%$ & Não & Não & Sim \\
\hline PB & $50 \%$ & Não & Não & Não \\
\hline PE & 37,4 & Não & Não & Não \\
\hline PI & $100 \%$ & $30 \%$ & Não & Sim \\
\hline $\mathrm{RN}$ & $50 \%$ & Não & Não & Não \\
\hline
\end{tabular}

(continua) 


\begin{tabular}{|c|c|c|c|c|}
\hline Estados & $\begin{array}{c}\text { Percentual a ser } \\
\text { alcançado até o } \\
\text { final da década }\end{array}$ & $\begin{array}{c}\text { Apresenta metas } \\
\text { à pós-graduação } \\
\text { stricto sensu }\end{array}$ & $\begin{array}{c}\text { Trata da oferta } \\
\text { de pós-graduação } \\
\text { gratuita para os } \\
\text { professores? }\end{array}$ & $\begin{array}{c}\text { Trata da realização } \\
\text { exclusiva em } \\
\text { Instituiçóes Públicas } \\
\text { de Ensino Superior }\end{array}$ \\
\hline SE & $50 \%$ & Não & Não & Não \\
\hline ES & $90 \%$ & Não & Não & Não \\
\hline MG & $50 \%$ & Não & Não & Não \\
\hline SP & $50 \%$ & Não & Não & Não \\
\hline RJ & $50 \%$ & Não & Não & Nim \\
\hline PR & $70 \%$ & Não & Não & Não \\
\hline RS & $80 \%$ & Não & Sim & Não \\
\hline SC & $75 \%$ & Não & Não & Não \\
\hline DF & $100 \%$ & $33 \%$ M. $3 \%$ D & Não & Não \\
\hline GO & $50 \%$ & Não & Não & Não \\
\hline MT & -- & Expandir & Não & Não \\
\hline MS & $60 \%$ & Não & & \\
\hline
\end{tabular}

FONTE: Planos Estaduais de Educação - Elaboração própria.

Buscamos verificar ainda nos planos estaduais e do Distrito Federal, se trataram da oferta gratuita de pós-graduação e se havia alguma previsão para que tal formação fosse promovida exclusivamente em Instituições Públicas de Ensino Superior. No primeiro caso, observamos que apenas os estados de Roraima, Rio Grande do Sul e Tocantins fazem alguma referência a essa gratuidade. Em relação a esse último estado, a referência sobre gratuidade vem acompanhada de uma observação que restringe o benefício aos professores da educação básica estadual e de uma limitação para o número de vagas por ano, como podemos notar na meta 20.7 ,

instituir, ao longo da vigência deste PEE/TO, parcerias com instituições de ensino superior, para oferta de cursos de formação continuada stricto sensu (mestrado e doutorado interinstitucional) gratuitos, aos professores da educação básica estadual, em todas as áreas de forma progressiva, com ampla divulgação das vagas, a partir do primeiro ano de vigência deste $\mathrm{PEE} / \mathrm{TO}$, sendo 120 (cento e vinte) vagas de mestrado, e 40 (quarenta) vagas de doutorado, [...] (TOCANTINS, 2015). 
Sobre a oferta ou realização exclusiva por Instituições de Ensino Superior (IES) públicas, observamos manifestação nesse sentido nos Planos Estaduais de Educação de 06 (seis) Estados: Tocantins, Maranhão, Piauí, Paraná, Rondônia e Rio Grande do Sul. No caso desses dois últimos, destaca-se a ressalva que a formação deve ser prioritariamente em instituições públicas.

O estudo realizado revela também outras particularidades, como o caso do estado da Bahia que mesmo assumindo a meta do PNE (2014-2024), de alcançar $50 \%$ de professores da educação básica com pós-graduação, não apresenta nenhuma estratégia relacionada. Ficando dúvidas sobre qual ou quais seriam as ações no âmbito daquela unidade federativa para se chegar ao objetivo. Sendo possível subentender, nesse caso, que a procura e a realização da pós-graduação deverá ser, possivelmente, uma busca individual de cada professor, sem qualquer ação do poder público.

Outra questão que gostaríamos de destacar diz respeito à questão do comprometimento dos estados em relação às bolsas de estudo para a pósgraduação. O que observamos nesse caso é que essa questão se tornou presente em quase todos os planos estaduais, porém, nos chamou atenção a forma genérica como, geralmente, é tratado o assunto. Boa parte dos planos destaca a ampliação de bolsas de estudo como estratégia para fomentar a pós-graduação, no entanto, como podemos notar no caso do PEE de São Paulo, em sua meta 16.1, o texto trata de "Promover e estimular a oferta de bolsas de estudo e a formação continuada para pós-graduação dos professores e demais profissionais da educação básica pública" (SÃO PAULO, 2016). Esse "estímulo" à oferta de bolsas não tem nenhuma previsão sobre a dimensão da política, sobre quantas bolsas serão criadas ou concedidas e se será ou não algo acessível para todos os professores da rede de ensino. Tal forma genérica de tratar a questão das bolsas de ensino se repete para a grande maioria dos PEE's.

Sobre a possibilidade de afastamento remunerado para formação, consideramos ser essa uma das questões mais importantes para garantir a ampliação da pós-graduação, sobretudo stricto sensu, junto aos professores da educação básica. Nesse sentido, apresentamos a seguir um levantamento, junto a todos os estados da federação e ao Distrito Federal, referente a abordagem dessa questão nos PEE's.

Como podemos observar, no Quadro 2, o primeiro aspecto apresentado diz respeito à garantia de licença remunerada para estudos. Inicialmente verificouse que nem todos os estados fizeram constar em seus planos o conteúdo da meta 18.4 do PNE (2014-2024). Ou seja, "prever, nos planos de carreira dos profissionais da educação dos estados, do Distrito Federal e dos Municípios, 
licenças remuneradas e incentivos para qualificação profissional, inclusive em nível de pós-graduação stricto sensu" (BRASIL, 2014) - META 18.4. Considerando os 26 estados e o Distrito Federal, percebe-se que 10 (dez), ou $37 \%$ não contemplam, em seus planos estaduais, nenhum tipo de licença para estudos. São eles: Acre, Amapá (2015), Pará (2015), Alagoas (2016), Bahia (2016), Paraíba (2015), Piauí, Espírito Santo, São Paulo e Mato Grosso.

Sendo necessário ressaltar que, em alguns casos, a garantia de licença para formação é colocada no plano de forma indireta. Esse, por exemplo, é o caso do estado do Acre que, na meta 16.8, propõe:

regulamentar, até o final do primeiro ano de vigência deste plano, políticas de formação em especialização stricto sensu, para docentes e não docentes das redes públicas da Educação Básica, garantindo as condições necessárias, financeiras e relativas à vida funcional, tanto no Estado, quando fora deste (ACRE, 2015).

Verificamos no caso acima que a "política de formação" que será regulamentada, embora ressalte-se que deverá garantir as condições necessárias, trata-se de um compromisso a ser firmado e especificado mais adiante. Em outros casos, como do PEE da Bahia, também não há uma diretriz clara para a concessão de licença, mas trata de "definições das prioridades para as licenças" como uma diretriz a ser considerada pelos Planos de Carreira dos profissionais da educação, como incentivo para formação continuada.

Quando analisamos os demais Planos Estaduais que preveem licença para estudo, constatamos que, com exceção do estado do Ceará, todos os demais tratam de uma licença remunerada. No caso desse estado, a referência que se faz sobre licença para estudos, na meta 16.8, propõe "normatizar a liberação dos profissionais da educação básica durante o período do curso stricto sensu acadêmico e profissional [...]" (CEARÁ, 2016) como uma estratégia para alcançar os $50 \%$ de professores com pós-graduação. 
QUADRO 2 - A LICENÇA REMUNERADA PARA FORMAÇÃO NOS PLANOS ESTADUAIS DE EDUCAÇÃO

\begin{tabular}{|c|c|c|c|c|c|c|c|}
\hline Estados & $\begin{array}{c}\text { Garante } \\
\text { licença } \\
\text { para } \\
\text { estudos }\end{array}$ & $\begin{array}{l}\text { Garante } \\
\text { licença } \\
\text { remune- } \\
\text { rada para } \\
\text { estudo }\end{array}$ & $\begin{array}{c}\text { Somente } \\
\text { para Pós- } \\
\text { graduação }\end{array}$ & $\begin{array}{c}\text { Somente } \\
\text { para pós- } \\
\text { graduação } \\
\text { stricto } \\
\text { sensu }\end{array}$ & $\begin{array}{c}\text { Estabelece } \\
\text { condicio- } \\
\text { nalidades }\end{array}$ & $\begin{array}{c}\text { Define } \\
\text { cotas no } \\
\text { universo de } \\
\text { professores } \\
\text { do estado }\end{array}$ & $\begin{array}{c}\text { Prevê } \\
\text { bolsas } \\
\text { além da } \\
\text { licença } \\
\text { remune- } \\
\text { rada }\end{array}$ \\
\hline \multicolumn{8}{|l|}{$\mathrm{AC}$} \\
\hline \multicolumn{8}{|l|}{$\mathrm{AP}$} \\
\hline $\mathrm{AM}$ & $X$ & $X$ & $X$ & & & & \\
\hline \multicolumn{8}{|l|}{ PA } \\
\hline RO & $X$ & $X$ & $X$ & & & & \\
\hline RR & $\mathrm{X}$ & $X$ & $\mathrm{X}$ & $\mathrm{X}$ & & & $X$ \\
\hline TO & $X$ & $X$ & $X$ & $X$ & & $X$ & \\
\hline \multicolumn{8}{|l|}{$\mathrm{AL}$} \\
\hline \multicolumn{8}{|l|}{$\mathrm{BA}$} \\
\hline $\mathrm{CE}$ & $\mathrm{X}$ & & & $X$ & & & \\
\hline MA & $X$ & $X$ & $X$ & $X$ & & & \\
\hline \multicolumn{8}{|l|}{ PB } \\
\hline $\mathrm{PE}$ & $X$ & $\mathrm{X}$ & $\mathrm{X}$ & & & & $X$ \\
\hline \multicolumn{8}{|l|}{ PI } \\
\hline $\mathrm{RN}$ & $X$ & $X$ & $X$ & $X$ & & & \\
\hline $\mathrm{SE}$ & $\mathrm{X}$ & $\mathrm{X}$ & $\mathrm{X}$ & $\mathrm{X}$ & & & \\
\hline \multicolumn{8}{|l|}{ ES } \\
\hline MG & $X$ & $X$ & & & & & \\
\hline \multicolumn{8}{|l|}{ SP } \\
\hline $\mathrm{RJ}$ & $\mathrm{X}$ & $\mathrm{X}$ & $X$ & $\mathrm{X}$ & $\mathrm{X}$ & & \\
\hline PR & $X$ & $X$ & $X$ & $X$ & & & \\
\hline $\mathrm{RS}$ & $X$ & $X$ & $X$ & $X$ & $X$ & & $X$ \\
\hline $\mathrm{SC}$ & $X$ & $X$ & $X$ & & & & \\
\hline DF & $\mathrm{X}$ & $\mathrm{X}$ & $\mathrm{X}$ & & & & $X$ \\
\hline GO & $X$ & $X$ & $X$ & & & & \\
\hline \multicolumn{8}{|l|}{ MT } \\
\hline MS & $\mathrm{X}$ & $\mathrm{X}$ & $\mathrm{X}$ & & & & $\mathrm{X}$ \\
\hline
\end{tabular}

FONTE: Planos Estaduais de Educação - Elaboração própria. 
Verificamos ainda que a licença remunerada para estudos está relacionada mais especificamente a pós-graduação. A exceção é o PEE do estado de Minas Gerais que não apresenta essa determinação de forma explícita. Os demais estados que asseguram o afastamento para formação, tratam da licença remunerada como uma possibilidade exclusiva para a pós-graduação. Sendo que, no caso de nove desses planos, a concessão de licença está restrita ao stricto sensu.

Verificamos também que dois estados apresentam condicionalidades para que os professores tenham direito à licença, este é o caso do Rio de Janeiro e do Rio Grande do Sul. No primeiro caso, a liberação para Mestrado e Doutorado será concedida "[...] desde que com o desenvolvimento de um projeto de pesquisa compatível com os interesses e necessidades da rede pública estadual, com a contrapartida de permanência do servidor após a licença por, no mínimo, 5 (cinco) anos de permanência no órgão de origem" (RIO DE JANEIRO, 2015) - META, 16.41. No segundo, o ingresso e incentivo para os professores da rede pública participarem de "mestrado e doutorado nas universidades públicas com bolsas e/ou afastamento integral para estudo, com recebimento de salário integral, sem restrições, [deverá acontecer] após a conclusão do estágio probatório" (RIO GRANDE DO SUL, 2015) - META 16.6.

Verificamos ainda quais planos estaduais buscavam garantir, além da licença remunerada, bolsa de estudos durante o período de afastamento para formação. Constatamos que nesse caso, apenas seis estados conseguem deixar totalmente explícito em seus planos estaduais que ambas, licença remunerada e bolsa de estudos, serão garantidas aos professores que pretenderem realizar pós-graduação. Sendo que a concessão de bolsas está relacionada, na maior dos casos não só ao stricto sensu, como também à realização da pós-graduação fora do domicílio.

Ressaltamos que outros estados também fazem referências a bolsas de estudo para os professores da educação básica, no entanto, nem sempre está relacionada a pós-graduação e não se trata de um benefício cumulativo com o afastamento remunerado para estudos. Esse é o caso do estado do Amapá, que não se refere a licença remunerada para seus professores, mas propõe: "criar programa de financiamento de bolsas de estudo para Pós-Graduação lato e stricto sensu que contemple todos os profissionais da Educação Básica, até o final da vigência do Plano Estadual de Educação-PEE” (AMAPÁ, 2015) - META, 20.5.

1 Importante destacar que no estado do Rio de Janeiro o PEE não consta como uma Lei aprovada e sancionada. $\mathrm{O}$ documento que tivemos acesso refere-se a uma versão preliminar do Plano. 


\section{Conclusão}

Percebe-se que o objetivo da pós-graduação se tornou algo presente na discussão sobre formação docente para a educação básica. De uma exigência apenas para formação de professores do ensino superior e para pesquisadores, com a meta 16 do PNE (2014-2024), a pós-graduação entrou na pauta como uma nova necessidade de formação para os professores da educação básica. No entanto, há uma clara evidência de que na realidade dos professores da educação básica, o horizonte possível é o da pós-graduação lato sensu. Da mesma forma, se evidencia como uma realidade preocupante, a flexibilização e a massificação desse tipo de formação, com sérios questionamentos sobre sua qualidade e sobre as consequências de sua mercantilização.

Do ponto de vista dos PEE's, de forma geral, assim como é colocado no PNE (2014-2024), a especificação da meta sobre a pós-graduação tem como cálculo o índice a ser alcançado com base na expansão do lato sensu. Sendo que o stricto sensu, mesmo não sendo uma realidade totalmente ausente dos planos estaduais, raramente conta com a definição de metas e estratégias para sua realização.

Verificamos, então, que a perspectiva da pós-graduação para formação docente na educação básica revela, de um lado, um possível avanço para formação e valorização docente, sobretudo quando acolhido nos planos de carreira, com consequente repercussão nos níveis salariais e de outro, um grande desafio a ser enfrentado. Nesse último caso, tendo em vista as condições específicas levantadas junto aos PEE's, devemos considerar, em primeiro lugar, como um grande desafio, as reais contribuições do modelo de pós-graduação predominante para o trabalho docente e para o enfrentamento dos problemas atuais da escola. Uma segunda preocupação, não menos importante, diz respeito às condições de efetiva realização, no sentido de que seja acessível e justo diante da realidade dos professores da educação básica no país.

No que se refere ao nível de contribuição para o trabalho docente, não há dúvidas que a desestruturação da pós-graduação lato sensu deixa uma grande interrogação sobre o verdadeiro significado ou contribuição do título de especialista para o enfrentamento da complexidade da escola. Tendo em vista as fragilidades do próprio processo de formação inicial, como se evidencia no diagnóstico dos cursos de licenciatura (GATTI, 2010; 2014), percebemos que a pós-graduação como parte da formação docente para educação básica deve ser repensada. Não deve ser apenas um título vazio ou uma marca no currículo para diferenciação individual. Se é que a pós-graduação passará a fazer parte 
de uma etapa da formação docente, ela deverá ter um sentido e um objetivo que ultrapasse as meras estatísticas, deve fazer sentido na vida do professor para além da ideologia do mérito, da disputa e da individualidade.

No que se refere as condições concretas para que os cursos de pósgraduação com qualidade sejam acessíveis aos docentes da educação básica, sobretudo os cursos de pós-graduação stricto sensu, há que se considerar a criação de condições concretas que possam ser de alcance mais abrangente. Essas possibilidades devem considerar a ampliação da oferta de mestrados e doutorados pelas universidades públicas, garantindo uma oferta de qualidade, em que a pesquisa, o aprofundamento teórico-crítico e o compromisso com a realidade concreta das escolas não estejam ausentes. Também deve considerar a necessária criação de condições adequadas para sua realização. $\mathrm{O}$ afastamento remunerado, a bolsa de ensino e a progressão na carreira, sem dúvida são itens indispensáveis para uma política efetiva de pós-graduação stricto sensu.

\section{REFERÊNCIAS}

ACRE. Lei n ${ }^{\circ} 2.965$, de 2 de julho de 2015. Aprova o Plano Estadual de Educação para o decênio 2015-2024 e dá outras providências. Diário Oficial do Estado do Acre, Rio Branco, v. 38, n. 11589, p. 5-61, 3 jul. 2015.

ALAGOAS. Lei n ${ }^{\circ} 7.795$, de 22 de janeiro de 2016. Aprova o Plano Estadual de Educação e dá outras providências. Diário Oficial do Estado de Alagoas, Maceió, 25 jan. 2016.

AMAPÁ. Lei no 1.907, de 24 de junho de 2015. Dispõe sobre o Plano Estadual de Educação - PEE, para o decênio 2015-2025, e dá outras providências. Diário Oficial do Estado do Amapá, Macapá, n. 5982, p. 2, 24 jun. 2015.

AMAZONAS. Lei ${ }^{\circ} 4.183$ de 26 de junho de 2015. Aprova o Plano Estadual de Educação do Amazonas e dá outras providências. Diário Oficial do Estado do Amazonas, Manaus, 26 jun. 2015.

BAHIA. Lei no 13.559, de 11 de maio de 2016. Aprova o Plano Estadual de Educação da Bahia e dá outras providências. Diário Oficial do Estado da Bahia, Salvador, 12 maio 2016.

BALL, Stephen J. Intelectuais ou técnicos? O papel indispensável da teoria nos estudos intelectuais. In: BALL, Stephen J.; MAINARDES, Jefferson. Politicas Educacionais: questões e dilemas (org.). São Paulo: Cortez, 2011. 
BRASIL. [Constituição (1988)]. Constituição da República Federativa do Brasil. Brasília, 1988. Brasília, DF: Presidência da República, [2020]. Disponível em: http:// www.planalto.gov.br/ccivil_03/constituicao/constituicaocompilado.htm. Acesso em: 30 set. 2020.

BRASIL. Presidência da República. Lei $n^{\circ} 9.394$, de 20 de dezembro de 1996. Estabelece as diretrizes e bases da educação nacional. Brasília, DF: Presidência da República, 20 dez. 1996. Disponível em: http://www.planalto.gov.br/ccivil_03/leis/L9394.htm. Acesso em: 26 jan. 2021.

BRASIL. Resolução CNE/CES n ${ }^{\circ}$ 1, de 3 de abril de 2001. Estabelece normas para o funcionamento de cursos de pós-graduação. Diário Oficial da União: seção 1, Brasília, DF, p. 12, 9 abr. 2001

BRASIL. Lei n ${ }^{\circ}$ 12.796, de 4 de abril de 2013. Altera a Lei no 9.394, de 20 de dezembro de 1996, que estabelece as diretrizes e bases da educação nacional, para dispor sobre a formação dos profissionais da educação e dar outras providências. Diário Oficial da União: seção 1, Brasília, DF, p. 1, 5 abr. 2013.

BRASIL. Presidência da República. Lei $n^{\circ} 13.005$, de 25 de junho de 2014. Aprova o Plano Nacional de Educação - PNE e dá outras providências. Brasília, DF: Presidência da República, 25 jun. 2014. Disponível em: http://www.planalto.gov.br/ccivil_03/_ato20112014/2014/lei/113005.htm. Acesso em: 26 jan. 2021.

BRASIL. Instituto Nacional de Estudos e Pesquisas Educacionais Anísio Teixeira. Relatório do $2^{\circ}$ Ciclo de Monitoramento das Metas do Plano Nacional de Educação 2018. Brasília, DF: INEP, 2018a.

BRASIL. Instituto Nacional de Estudos e Pesquisas Educacionais Anísio Teixeira. Sinopse Estatística da Educação Básica - 2017. Brasília, DF: INEP, 2018b. Disponível em: http://inep.gov.br/sinopses-estatisticas-da-educacao-basica. Acesso em: 01 nov. 2020.

CALAZANS, Maria Julieta Costa. Planejamento na educação no Brasil: novas estratégias em busca de novas concepções. In: KUENZER, Acácia Zeneida; CALAZANS, Maria Julieta Costa; GARCIA, Walter. Planejamento e educação no Brasil. 3. ed. São Paulo: Cortez Editora, 1996. p. 11-33. (Questões da nossa época, v. 21).

CEARÁ. Lei ${ }^{\circ} 16.025$, de 30 de maio de 2016. Aprova o Plano Estadual de Educação (2016/2024). Diário Oficial do Estado do Ceará, Fortaleza, v. 8, n. 101, p. 1-19, 1 jun. 2016.

CUNHA, Luiz Antonio C. R. A pós-graduação no Brasil: função técnica e função social. Rev. adm. empres. São Paulo, v.14, n. 5, p. 66-70, set./out. 1974.

DISTRITO FEDERAL. Lei no 5.499, de 14 julho de 2015. Aprova o Plano Distrital de Educação - PDE e dá outras providências. Diário Oficial do Distrito Federal, Brasília, DF, n. 135,15 jul. 2015

ESPÍRITO SANTO. Lei $\mathrm{n}^{\circ}$ 10.382, de 25 de junho de 2015. Aprova o Plano Estadual de Educação do Espírito Santo e dá outras providências. Diário Oficial do Estado do Espirito Santo, Vitória, n. 2429, p. 1-12, 25 jun. 2015. 
FONSECA, Dirce Mendes da. Contribuições ao debate da pós-graduação lato sensu. Revista Brasileira de Pós-Graduação, Brasília, v. 1, n. 2, p. 173-182, nov. 2004.

GATTI, Bernardete Araújo. Formação inicial de professores para a educação básica: pesquisas e políticas educacionais. Estudos de Avaliação Educacional, São Paulo, v. 25, n. 57, p. 24-54, jan./abr. 2014.

GATTI, Bernardete Araújo. Formação de Professores no Brasil: Características e Problemas. Educ. Soc., Campinas, v. 31, n. 113, p. 1355-1379, out./dez. 2010.

GOIÁS. Lei no 18.969, de 22 de julho de 2015. Aprova o Plano Nacional de Educação para o decênio 2015.2025 e dá outras providências. Diário Oficial do Estado do Goiás, Goiânia, v. 178, n. 22129, p. 1-17, 27 jul. 2015.

KUZUYABU, Marina. Pós-graduação é o setor que mais cresce. Revista Ensino Superior, [s.l.], 246 ed. 2 mar. 2020. Disponível em: https://revistaensinosuperior.com.br/posgraduacao-semesp-pes/. Acesso em: 02 dez. 2020.

MARANHÃO. Lei n ${ }^{\circ}$ 10.099, de 11 de junho 2014. Aprova o Plano Estadual de Educação do Estado do Maranhão e dá outras providências. Diário Oficial do Estado do Maranhão, São Luís, v. 108, n. 111, p. 29, 11 jun. 2014.

MATO GROSSO DO SUL. Lei n ${ }^{\circ}$ 4.621, 22 de dezembro de 2014. Aprova o Plano Estadual de Educação do Mato Grosso do Sul e dá outras providências. Diário Oficial do Estado do Mato Grosso do Sul, Campo Grande, n. 8828, p. 6, 26 dez. 2014.

MATO GROSSO. Lei n ${ }^{\circ} 10.111$, de 6 de junho de 2014. Dispõe sobre a revisão e alteração do Plano Estadual de Educação, instituído pela Lei n ${ }^{\circ} 8.806$, de 10 de janeiro de 2008. Diário Oficial do Estado do Mato Grosso, Cuiabá, 6 jun. 2014.

PARÁ. Lei no 8.186, de 23 de junho de 2015. Aprova o Plano Estadual de Educação - PEE e dá outras providências. Diário Oficial do Estado do Pará, Belém, v. 125, n. 32913, p. 1-32, 24 jun. 2015.

PARAÍBA. Lei no 10.488 , de 23 de junho de 2015. Aprova o Plano Estadual de Educação e dá outras providências. Diário Oficial do Estado da Paraíba, João Pessoa, 24 jun. 2015.

PARANÁ. Lei n ${ }^{\circ} 18.492$, de 24 de junho de 2015. Plano Estadual de Educação e adoção de outras providências. Diário Oficial do Estado do Paraná, Curitiba, n. 9.479, 25 jun. 2015.

PERNAMBUCO. Lei no 15.533, de 23 de junho de 2015. Aprova o Plano Estadual de Educação. Diário Oficial do Estado de Pernambuco, Recife, p. 3, 24 jun. 2015.

PIAUÍ. Lei n ${ }^{\circ}$ 6.733, de 17 de dezembro de 2015. Aprova o Plano Estadual de Educação - PEE e dá outras providências. Diário Oficial do Estado do Piauí, Teresina, v. 84, n. 239, p. 1-17, 21 dez. 2015.

RIO DE JANEIRO (Estado). Versão preliminar Plano Estadual de Educação do estado do Rio de Janeiro 2015 -2024. Disponível em: https://www.angra.rj.gov.br/downloads/ SEC/PME/PEE\%20-\%20Vers\%C3\%A3o\%20preliminar.pdf. Acesso em: 12 abr. 2019. 
RIO GRANDE DO SUL. Lei no 14.705 , de 25 de junho de 2015. Institui o Plano Estadual de Educação - PEE. Diário Oficial do Estado. Porto Alegre, n. ${ }^{\circ}$ 120, 26 jun. 2015.

RONDÔNIA. Lei no 3.565, de 3 de junho de 2015. Institui o Plano Estadual de Educação de Rondônia. Diário Oficial do Estado de Rondônia, Porto Velho, n. 3565, 3 jun. 2015.

RORAIMA. Lei n ${ }^{\circ} 1.008$, de 3 setembro de 2015. Aprova o Plano Estadual de Educação 2014/2024 (PEE) e dá outras providências. Diário Oficial do Estado de Roraima, Boa Vista, v. 27, n. 3596, p. 6-26, 3 set. 2015.

SANTA CATARINA. Lei nº 16.794, de 14 de dezembro de 2015. Aprova o Plano Estadual de Educação para o decênio e dá outras providências. Diário Oficial do Estado de Santa Catarina, Florianópolis, v. 81, n. 20205, p. 1-10, 15 dez. 2015.

SÃO PAULO (Estado). Lei n ${ }^{\circ} 16.279$, de 8 de julho de 2016. Aprova o Plano Estadual de Educação de São Paulo e dá outras providências. Diário Oficial do Estado de São Paulo, São Paulo, 9 jul. 2016.

SAVIANI, Demerval. A pós-graduação em educação e a especificidade da pesquisa educacional. Argumentos Pró-Educação, Pouso Alegre, v. 2, n. 4, p. 3-19, jan./abr. 2017

SILVA, Antônia Almeida; JACOMINI, Márcia Aparecida. A pós-graduação e a pesquisa sobre/na educação básica relações e proposições. Educação e Pesquisa, São Paulo, v. 43, n. 3, p. 629-646, jul./set. 2017. http://dx.doi.org/10.1590/S1517-9702201604143113.

TOCANTINS. Lei n ${ }^{\circ} 2.977$, de 08 de julho de 2015. Aprova o Plano Estadual de Educação do Tocantins - PEE/TO (2015-2025), e adota outras providências. Publicada no Diário Oficial do Estado do Tocantis, Palmas, n. 4.411, 9 jul. 2015.

Texto recebido em 11/05/2020.

Texto aprovado em 27/01/2021. 